\title{
Commercial Testosterone Preparations: What is the Risk for Male Fertility?
}

Jared L Moss, Lindsey E Crosnoe and Edward D Kim*

University of Tennessee Graduate School of Medicine, USA

\begin{abstract}
Background: The populations of symptomatic hypogonadal men and men fathering children at later ages are both increasing. Infertility is a potentially detrimental and preventable side effect of exogenous testosterone therapy. While the use of commercially available testosterone products to treat hypogonadism are increasing, very little is known about their specific effects on fertility.
\end{abstract}

Methods: A PubMed literature search for the years 1944-2013 was completed focusing on studies examining the effect of testosterone replacement therapy on male fertility. A review of U.S. Food and Drug Administration Prescribing Information was performed on commercial testosterone products in the United States. The manufacturers for the testosterone products were individually contacted for additional information regarding testosterone replacement, spermatogenesis, and male infertility. Lastly, the website www.clinicaltrials.gov was accessed for active clinical trials assessing the effect of testosterone preparations on spermatogenesis and male fertility.

Results: All commercial companies referred inquiries regarding spermatogenesis and male fertility to their Prescribers Information Warning and Precautions Sections. These sections consist of a general statement explaining that adverse effects on spermatogenesis may be seen at high doses. Most of these companies have not performed product specific studies examining the effects of their preparation on spermatogenesis. As a result, the warnings used are often extrapolated from previous studies examining different testosterone products. A few testosterone preparations have product specific data, but the data is scant and very limited.

Conclusion: Currently, scant data exist that are product specific to the commercial testosterone being prescribed to the hypogonadal male seen in clinical practice. More studies are needed that examine these specific products' effects on spermatogenesis before one can make educated recommendations regarding use. Men desiring fertility should avoid exogenous testosterone use.

Keywords: Testosterone; Spermatogenesis; Infertility; Hypogonadism

\section{Introduction}

The treatment of male hypogonadism with commercial testosterone preparations has increased $170 \%$ over the past five years [1]. The Endocrine Society defines hypogonadism as signs/symptoms and a total testosterone level less than 300 (ng/dL) [2]. Because testosterone levels decline with age, older men are more likely to be treated with exogenous testosterone therapy and it is estimated that more than 6.5 million aging men in the U.S. will have symptomatic androgen deficiency by 2025 [3]. At the same time, men are fathering children at a later age than ever before. In 1970, less than 15\% of all men fathering children were over age 35 . Today, that percentage has risen to nearly $25 \%$. Even among men aged 50 to 54 years, there has been a notable increase in fatherhood [4].

Many clinicians are unaware that exogenous testosterone suppresses the hypothalamic-pituitary-gonadal axis (HPG) and may result in impaired spermatogenesis in men of any age. For example, in a recent survey of U.S. urologists, Ko et al. [5] reported that approximately $25 \%$ have used exogenous testosterone to treat low testosterone levels associated with male infertility. While the use of commercially available testosterone products to treat hypogonadism is increasing, very little is known about their specific effects on fertility. Most of this information has been extrapolated from the data initially used to obtain testosterone's FDA approval in 1953. This paper will review commercially available testosterone therapies in the U.S. and their impact on male fertility.

\section{Methods}

Data acquisition consisted of four components. First, a PubMed literature search for the years 1944-2013 was completed focusing on studies examining the effect of testosterone replacement therapy (TRT) on male fertility. Second, a review of U.S. Food and Drug Administration (FDA) Prescribing Information (PI) was performed on commercially available testosterone products in the United States. Third, inquiries were made to manufacturing companies of commercial testosterone products and the U.S. FDA for additional information regarding testosterone replacement, spermatogenesis, and male infertility. Fourth, the website www.clinicaltrials.gov was accessed for active clinical trials assessing the effect of testosterone preparations on spermatogenesis and male fertility.

\section{Results}

\section{Prescribing information (pi)}

Commercial companies referred inquiries regarding spermato-

*Corresponding author: Edward Kim, University of Tennessee Graduate Schoo of Medicine, 1928 Alcoa Highway, Suite 222 Knoxville, TN 37920, USA, Tel: 865305-9254; Fax: 865-305-9716; E-mail: ekim@utmck.edu

Received May 15, 2013; Accepted June 17, 2013; Published June 21, 2013

Citation: Moss JL, Crosnoe LE, Kim ED (2013) Commercial Testosterone Preparations: What is the Risk for Male Fertility? J Steroids Horm Sci 4: 113 doi:10.4172/2157-7536.1000113

Copyright: ( 2013 Moss JL, et al. This is an open-access article distributed unde the terms of the Creative Commons Attribution License, which permits unrestricted use, distribution, and reproduction in any medium, provided the original author and source are credited. 
Citation: Moss JL, Crosnoe LE, Kim ED (2013) Commercial Testosterone Preparations: What is the Risk for Male Fertility? J Steroids Horm Sci 4 113. doi:10.4172/2157-7536.1000113

genesis and male fertility to their PI "Warning and Precautions Section."For commercial testosterone products, these Warnings and Precautions consist of a general statement explaining that adverse effects on spermatogenesis may be seen at high doses. The wording of these statements across all commercial products is very similar and most do not cite sources to support their warnings. Most of these companies have not performed product specific studies examining the effects of their preparation on spermatogenesis. As a result, the warnings used are often extrapolated from previous studies examining different testosterone products, which may or may not be similar to their product. When sources were cited, most were studies examining various testosterone derivatives which are similar to the commercial product, but not identical. A few testosterone preparations have product specific data, but the data is scant and very limited.

The PIs for Axiron ${ }^{\circledR}$ (testosterone), Testim ${ }^{\circledR}$ (testosterone gel), Depo $^{\circledR}$-testosterone (testosterone cypionate), Delatestryl ${ }^{\circledR}$ (testosterone enanthate) all state in general terms that large doses of exogenous androgens may lead to adverse effects on semen parameters (Table 1). These statements weresimilar from all companies. Cited sources were not provided to support these warnings. Their warnings have been extrapolated from prior testosterone studies.

Fortesta's ${ }^{\mathrm{TM}}$ (testosterone) PI warns that large doses of exogenous androgens may cause impaired semen parameters via suppression of FSH via HPG axis (Table 1). Sources cited included a Liu et al. [6] review of spermatogenic recovery after hormonal contraception and a study by Mauss et al. [7] which examined reversibility of spermatozoa suppression by testosterone enanthate. The former is a contraceptive study which uses supra-therapeutic testosterone dosing and neither were product specific to Foresta ${ }^{\mathrm{TM}}$.

The PI for AndroGel ${ }^{\circledR} 1 \%$ (testosterone gel) contains a product specific, prospective 6 month study. This study evaluated the effects of AndroGel ${ }^{\circledR} 1 \%$ (50mg of testosterone gel) daily on sperm parameters and was presented as an abstract at the 11th European Congress of Endocrinology [8]. Sixteen hypogonadal men, ages 45 to 58, semen parameters were examined only after 6 months of daily dosing. No information was available regarding semen parameters pre-treatment. After 6 months of therapy various medians were recorded. The median

\begin{tabular}{|c|c|c|c|c|}
\hline Commercial Product & & FDA Precaution & & Web page \\
\hline \multicolumn{5}{|c|}{ TOPICAL } \\
\hline $\begin{array}{l}\text { Androgel }{ }^{\circledR} \\
\text { AbbVie Inc. } \\
\text { North Chicago, IL }\end{array}$ & \multicolumn{2}{|c|}{$\begin{array}{l}\text { Large doses of exogenous androgens may lead to suppression of } \\
\text { spermatogenesis or azoospermia through feedback inhibition of pituitary } \\
\text { FSH. This could possibly lead to adverse effects on semen parameters, } \\
\text { including sperm count. }\end{array}$} & \multicolumn{2}{|c|}{ http://www.androgel.com/default.aspx } \\
\hline $\begin{array}{l}\text { Androderm® } \\
\text { Watson } \\
\text { Pharmaceuticals, Inc. } \\
\text { Oakville, Ontario, } \\
\text { Canada }\end{array}$ & \multicolumn{2}{|c|}{$\begin{array}{l}\text { Taking testosterone may lead to a condition in which there are no sperm in } \\
\text { the semen }\end{array}$} & \multicolumn{2}{|c|}{ http://www.androderm.com/ } \\
\hline $\begin{array}{l}\text { Testim® } \\
\text { Auxilium } \\
\text { Pharmaceuticals, Inc. } \\
\text { Malvern, PA }\end{array}$ & \multicolumn{2}{|c|}{$\begin{array}{l}\text { At large doses of exogenous androgens, spermatogenesis may also be } \\
\text { suppressed through feedback inhibition of pituitary follicle-stimulating } \\
\text { hormone (FSH). } \\
\text { In large doses, Testim may lower your sperm count. }\end{array}$} & \multicolumn{2}{|c|}{ http://www.testim.com/ } \\
\hline $\begin{array}{l}\text { Fortesta }{ }^{\circledR} \\
\text { Endo Pharmaceuticals } \\
\text { Inc. Malvern, PA }\end{array}$ & \multicolumn{2}{|c|}{$\begin{array}{l}\text { With large doses of exogenous androgens, includingFortesta, } \\
\text { spermatogenesis may be suppressed through feedback inhibition of } \\
\text { pituitary follicle-stimulating hormone, which could possibly lead to adverse } \\
\text { effects on semen parameters including sperm count. } \\
\text { In large doses, Fortesta may lower your sperm count. } \\
\text { The administration of exogenous testosterone has been reported to } \\
\text { suppress spermatogenesis in the rat, dog, and non-human primates which } \\
\text { was reversible on cessation of the treatment. }\end{array}$} & \multicolumn{2}{|c|}{ http://www.fortestagel.com/ } \\
\hline $\begin{array}{l}\text { Axiron® } \\
\text { Lilly USA, LLC. } \\
\text { Indianapolis, IN }\end{array}$ & \multicolumn{2}{|c|}{$\begin{array}{l}\text { At large doses, spermatogenesis may be suppressed which could possibly } \\
\text { lead to adverse effects on semen parameters including, sperm count. }\end{array}$} & \multicolumn{2}{|c|}{ http://www.axironmd.com/Pages/home.aspx } \\
\hline \multicolumn{5}{|l|}{ BUCCAL } \\
\hline $\begin{array}{l}\text { Striant } \circledast \\
\text { Mipharm S.p.A } \\
\text { Milan, Italy }\end{array}$ & \multicolumn{2}{|c|}{$\begin{array}{l}\text { During exogenous administration of androgens, endogenous testosterone } \\
\text { release may be inhibited through feedback inhibition of pituitary luteinizing } \\
\text { hormone (LH). At large doses of exogenous androgens, spermatogenesis } \\
\text { may also be suppressed through feedback inhibition of pituitary follicle- } \\
\text { stimulating hormone (FSH). }\end{array}$} & \multicolumn{2}{|c|}{$\begin{array}{l}\text { http://www.actientpharma.com/filebin/pdf/products/58816-10_ } \\
\text { Striant_full_PI_4pager.pdf }\end{array}$} \\
\hline \multicolumn{5}{|c|}{ INTRAMUSCULAR/SUBCUTANEOUS } \\
\hline \multicolumn{2}{|c|}{$\begin{array}{l}\text { Testosterone enanthate } \\
\text { Hikma Pharmaceutical (Portugal), S.A. }\end{array}$} & \multicolumn{2}{|c|}{$\begin{array}{l}\text { During exogenous administration of androgens, endogenous } \\
\text { testosterone release is inhibited through feedback inhibition of } \\
\text { pituitary luteinizing hormone (LH). Large doses of exogenous } \\
\text { androgens may suppress spermatogenesis through inhibition of } \\
\text { pituitary follicle stimulating hormone (FSH). }\end{array}$} & http://www.drugs.com/pro/testosterone-enanthate.html \\
\hline \multicolumn{2}{|c|}{$\begin{array}{l}\text { Testosterone cypionate } \\
\text { West-ward pharmaceutical corp. Eatontown, } \\
\text { NJ } 07724 \text { USA }\end{array}$} & \multicolumn{2}{|l|}{$\begin{array}{l}\text { Exogenous administration of androgens may lead to } \\
\text { azoospermia. }\end{array}$} & http://www.drugs.com/pro/testosterone-cypionate.html \\
\hline \multicolumn{2}{|c|}{$\begin{array}{l}\text { Testopel® } \\
\text { Slate Pharmaceuticals Inc. } \\
\text { Durham, NC }\end{array}$} & \multicolumn{2}{|c|}{$\begin{array}{l}\text { During exogenous administration of androgens, endogenous } \\
\text { testosterone release is inhibited through feedback inhibition of } \\
\text { pituitary luteinizing hormone (LH). At large doses of exogenous } \\
\text { androgens, spermatogenesis may also be suppressed through } \\
\text { feedback inhibition of pituitary follicle stimulating hormone } \\
\text { (FSH). }\end{array}$} & http://www.testopel.com/ \\
\hline
\end{tabular}

Table 1: Prescribing Information for U.S. commercial testosterone preparations. 
sperm count was $37.5 \mathrm{million} / \mathrm{ml}$, motility $14.0 \%$, percent of normal forms 7.0 , viability $86.0 \%$. They concluded that AndroGel $1 \%{ }^{\circledR}$ treatment had a more pronounced negative effect on motility and morphology of spermatozoa, and a slight negative effect on sperm count.

\section{Pubmed review}

Few studies have examined the effects of commercial testosterone products on fertility. Kaminetsky et al. compared testosterone gel $\left(\right.$ Testim $\left.^{\circledR}\right)$ and enclomiphene citrate (EC), a derivative of clomiphene citrate (CC) [9]. Clomiphene citrate is a selective estrogen receptor modulator (SERM) that is FDA approved to induce ovulation in women. SERMs are used off-label to treat hypogonadal men interested in preserving fertility potential. In this trial, 12 men with secondary hypogonadism were administered either a daily dose of testosterone gel or $25 \mathrm{mg}$ of EC orally each day. Men who received EC after discontinuation of topical testosterone all had improved total testosterone, LH/FSH, and sperm parameters. In contrast, the testosterone gel alone group suppressed $\mathrm{FSH} / \mathrm{LH}$ and was ineffective for raising sperm counts above $20 \times 10^{6} / \mathrm{mL}$. They concluded that EC increased testosterone and sperm counts via the HPG axis.

At the 2013 American Urological Association meeting Samplaski et al. [10] from Toronto, Canada presented an abstract which examined the short and long term effects of exogenous testosterone on male fertility. Four thousand and four hundred men were evaluated for male infertility and $56(1.3 \%)$ of these men reported being on exogenous testosterone at the time of their initial office visit. These men were placed on exogenous testosterone secondary to their hypogonadism and poor semen analysis. Thirty-four of the 56 (60\%) men tested were azoospermic while on testosterone at presentation. While on testosterone, the average serum testosterone was $14.74 \mathrm{nmol} / \mathrm{L}$, and sperm count $4.11 \times 10^{6} / \mathrm{mL}$. After testosterone discontinuation, the average testosterone was $11.79 \mathrm{nmol} / \mathrm{L}$, and sperm count $26.84 \times 10^{6} /$ $\mathrm{mL}$. They noted that testosterone cessation resulted in a fairly rapid increase in sperm counts. However, a subset of men with no other cause for the azoospermia remained azoospermic despite testosterone cessation. They concluded men in their reproductive years should be discouraged from using exogenous testosterone, unless medically required. Also, most infertile men who have no other cause for azoospermia will recover spermatogenesis when testosterone is discontinued.

\section{Contraceptive trials}

Contraceptive studies have not used dosing consistent with commercially available testosterone preparations in the U.S. These studies instead have used supra-therapeutic dosing for the sole purpose of completely suppressing sperm production. Results from these studies are not directly applicable to present commercial studies, but represent the best existing data. Additionally, these studies have a high preponderance of men of Chinese ethnicity who may not be comparable to men in the U.S.

A study by the World Health Organization (WHO) Task Force evaluated 271 men who received $200 \mathrm{mg}$ of testosterone enanthate weekly [11]. This dose is approximately twice the normal dose for hypogonadal men seen clinically. After 6 months, 157 (65\%) of men were azoospermic, and the mean time to azoospermia was 120 days. After 6 months of treatment, the patients entered the recovery phase where exogenous testosterone was discontinued. While $84 \%$ of men were able to achieve a sperm density $>20$ million $/ \mathrm{mL}$ after a median of 3.7 months, only $46 \%$ of patients were able to achieve their baseline sperm density.

$\mathrm{Gu}$ et al. [12] from China administered testosterone undecanoate $500 \mathrm{mg}$ monthly for 30 months to a group of 855 Chinese men. Ninetyfive percent of men achieved azoospermia or severe oligozoospermia $\left(<1 \times 10^{6} \mathrm{sperm} / \mathrm{ml}\right)$, and the median time to onset of azoospermia or severe oligozoospermia was 108 days. The median time to recovery of spermatogenesis calculated from the beginning of the recovery phase was 196 days. It should be noted that this study was a contraceptive trial, which used supra-therapeutic dosing.

In a another testosterone contraceptive study, notably of Caucasian men, Anderson et al examined 56 men who were administered testosterone enanthate $200 \mathrm{mg}$ intramuscular injections (IM) weekly for 65 weeks [13]. Suppression of sperm production to oligozoospermic levels $\left(<5 \times 10^{6} / \mathrm{ml}\right)$ ranged from 10 to 26 weeks. Importantly, the recovery of spermatogenesis to pre-treatment levels was achieved in most men by 24 weeks after cessation of testosterone. The men who achieved azoospermia had a slower return to pre-treatment sperm concentration when compared to oligozoospermic partial responders. This study also suggests that FSH and inhibin B may be markers related to differential recovery rates of spermatogenesis.

Liu et al. [6] performed a multivariate analysis of 30 studies, published between 1990-2005, which addressed sperm recovery after session of exogenous testosterone. Included were 1549 healthy eugonadal men, aged 18-51 years, who were treated with androgens or androgens plus progestagen. Higher rates of recovery were identified with older age, Asian origin, shorter treatment duration, shorter-acting testosterone preparations, higher sperm concentrations at baseline, faster suppression of spermatogenesis, and lower LH levels at baseline. The typical probability of recovery to 20 million per $\mathrm{mL}$ was $67 \%$ within 6 months, $90 \%$ within 12 months, $96 \%$ within 16 months, and $100 \%$ within 24 months (Table 2).

\section{FDA}

Contact was made with the FDA to determine what data were reviewed for the initial testosterone approval in 1953. Other areas of desired investigation include why only pharmacokinetic data are

\begin{tabular}{|c|c|c|c|c|}
\hline \multicolumn{3}{|c|}{ Probability of Recovery (\%) } \\
\hline & Within 6 months & Within 12 months & Within 16 months \\
\hline Individual Baseline & $54 \%(46-60)$ & $83 \%(75-89)$ & $95 \%(89-98)$ \\
\hline 20 million per $\mathrm{mL}$ & $67 \%(61-72)$ & $90 \%(85-93)$ & $96 \%(92-98)$ \\
\hline 10 million per $\mathrm{mL}$ & $79 \%(73-83)$ & $95 \%(92-97)$ & $99 \%(97-100)$ \\
\hline 3 million per $\mathrm{mL}$ & $89 \%(84-92)$ & $98 \%(95-99)$ & $100 \%{ }^{*}$ \\
\hline
\end{tabular}

Adapted from Liu PY et al. [6] 
Citation: Moss JL, Crosnoe LE, Kim ED (2013) Commercial Testosterone Preparations: What is the Risk for Male Fertility? J Steroids Horm Sci 4: 113. doi: $10.4172 / 2157-7536.1000113$

1. Minimal product specific data exist examining effects of current testosterone preparations on spermatogenesis.

2. Warnings regarding the effects of today's testosterone preparations on spermatogenesis are largely extrapolated from studies which are not product specific.

3. Testosterone products are similar, but not identical.

4. Existing data examining the effects of testosterone on fertility are limited by supra-therapeutic dosing, a homogenous population, and little fecundity data.

5. More product specific studies examining the effects on fertility are needed.

6. Men desiring future fertility should avoid exogenous testosterone preparations.

Table 3: Recommendations.

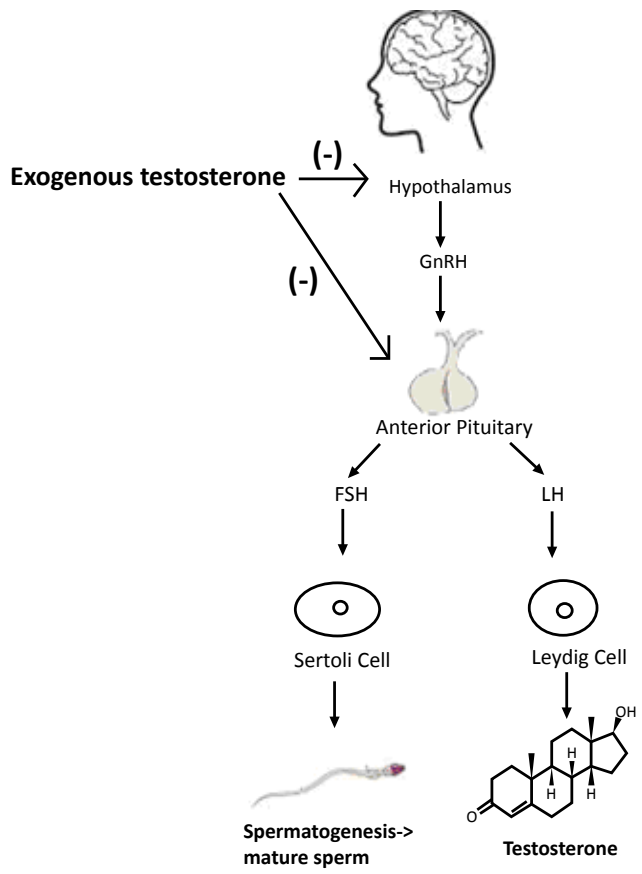

Figure 1: Mechanism of Action

required for future drugs within this same class. We were unable to obtain this information from the FDA despite our initial contact and multiple follow up attempts.

\section{Discussion}

Because the populations of symptomatic hypogonadal men and men fathering children at later ages are increasing, infertility is a potentially detrimental and preventable side effect of exogenous testosterone therapy. Data are limited by the supra-therapeutic dosing of contraceptive trials, homogenous study populations, and use of testosterone derivatives. While this limited literature suggests that exogenous testosterone negatively impacts semen parameters, there are little data to effectively prove this point. In layman's terms, we really have very little idea how detrimental commercial testosterone preparations are on male fertility potential. Future studies are needed to provide a more realistic idea of what the hypogonadal male seen in clinical practice can expect from a fertility standpoint.

\section{History}

The reason studies examining the effect of commercial testosterone preparations on spermatogenesis have not been performed is they have not been required for FDA-approval. In 1953, testosterone was approved by the FDA for the treatment of hypogonadism [14]. Approval of newer formulations since that time has been largely dependent on pharmacokinetic, and not safety data. Today, there are multiple FDA-approved testosterone products available (Table 1). Gels currently represent 70 percent of the testosterone replacement therapy (TRT) market in the United States $[15,16]$. While the initial testosterone preparations and today's commercial preparations are similar, they are not the identical [17]. Multiple testosterone derivatives have been examined over the past seventy years which have helped to create a foundation for understanding the potential side effects of testosterone therapy. However, very little of this data are specific to commercial preparations showing they are safe. The current commercial TRT companies are primarily relying on data published from studies using products which are similar, and studies which lacked a clinical dosing regimen. This deficiency of product specific data makes it difficult for a physician to provide appropriate expectations to their patients from a fertility standpoint.

\section{Mechanism of action}

Because many physicians are unaware that exogenous testosterone can suppress spermatogenesis, it is important to review this mechanism. Testosterone inhibits both GnRH and gonadotropin secretion which results in negative feedback on the HPG axis. This action suppresses the secretion of FSH and LH by the hypothalamus (Figure 1). Suppression of gonadotropins results in a decrease in intratesticular testosterone levels (ITT) and overall testosterone production. Normally, ITT concentrations are roughly fifty to one hundred times serum levels and are an absolute prerequisite for normal spermatogenesis. Exogenous testosterone therapies can suppress ITT production to such a degree 
Citation: Moss JL, Crosnoe LE, Kim ED (2013) Commercial Testosterone Preparations: What is the Risk for Male Fertility? J Steroids Horm Sci 4: 113. doi:10.4172/2157-7536.1000113

that spermatogenesis can be dramatically compromised and even result in azoospermia $[18,19]$.

\section{Limitations of literature}

Extrapolating results from contraceptive studies using large doses of exogenous testosterone is problematic for several reasons. Men seen in clinical practice are not administered the high dose testosterone regimens used in the contraceptive studies, and much of these data analyze men primarily of Asian origin. These studies, therefore, may not truly reflect what American men taking a much lower dose can expect. These data also suggest this effect is reversible with cessation of exogenesis testosterone within two years for most men [6] (Table 2). This observed time to recovery may be helpful for patient counseling, but does not account for outliers who are not able to recover adequate sperm concentrations.

Another significant limitation of the published literature is a lack of pregnancy outcome data. The published literature represents the best available evidence to date regarding the recovery of spermatogenesis after testosterone supplementation, but it is important to emphasize that semen analysis data do not correlate with pregnancy outcomes and that none of the literature assesses time to fecundity.

\section{Conclusion}

Today, the male population is aging and men are fathering children at a later age. Many men in this group may be seeking TRT and are unaware of the potential negative consequences regarding their fertility. Currently, scant data exist that are product specific to the commercial testosterone being prescribed to the hypogonadal male seen in clinical practice. More studies are needed that examine these specific products' effects on spermatogenesis before one can make educated recommendations regarding use (Table 3).

\section{References}

1. Nigro N, Christ-Crain M (2012) Testosterone treatment in the aging male: myth or reality? Swiss Med Wkly 142: w13539.

2. www.endo-society.org/guidelines

3. Katz DJ, Nabulsi O, Tal R, Mulhall JP (2012) Outcomes of clomiphene citrate treatment in young hypogonadal men. BJU Int 110: 573-578.

4. Fisch H,Braun S (2005) The Male Biological Clock: the Startling News about Aging and Fertility in Men. New York, USA.
5. Ko EY, Siddiqi K, Brannigan RE, Sabanegh ES Jr (2012) Empirical medical therapy for idiopathic male infertility: a survey of the American Urological Association. J Urol 187: 973-978.

6. Liu PY, Swerdloff RS, Christenson PD, Handelsman DJ, Wang C, et al. (2006) Rate, extent, and modifiers of spermatogenic recovery after hormonal male contraception: an integrated analysis. Lancet 367: 1412-1420.

7. Mauss J, Börsch G, Richter E, Bormacher K (1978) Demonstration of the reversibility of spermatozoa suppression by testosterone oenanthate. Andrologia 10: 149-153.

8. Mskhalaya G, Tishova Y, Vadov V, Gusakova D, Kalinchenko S (2009) Spermatogenesis in men with late-onset hypogonadism, receiving testosterone gel. Abstract presented at: 11th European Congress of Endocrinology April 2529, Istanbul, Turkey.

9. Kaminetsky J, Werner M, Fontenot G, Wiehle RD (2013) Oral enclomiphene citrate stimulates the endogenous production of testosterone and sperm counts in men with low testosterone: comparison with testosterone gel. J Sex Med 10: 1628-1635.

10. Samplaski M, Loai Y, Lo K, Grober E, Jarvi K (2013) Testosterone Use in the Male Infertility Population: Short and Longer Term Effects on Semen and Hormonal Parameters.

11. (1990) Contraceptive efficacy of testosterone-induced azoospermia in norma men. World Health Organization Task Force on methods for the regulation of male fertility. Lancet 336: 955-959.

12. Gu Y, Liang X, Wu W, Liu M, Song S, et al. (2009) Multicenter contraceptive efficacy trial of injectable testosterone undecanoate in Chinese men. J Clin Endocrinol Metab 94: 1910-1915.

13. Anderson RA, Wallace EM, Groome NP, Bellis AJ, Wu FC (1997) Physiologica relationships between inhibin $B$, follicle stimulating hormone secretion and spermatogenesis in normal men and response to gonadotrophin suppression by exogenous testosterone. Hum Reprod 12: 746-751.

14. Hoberman JM, Yesalis CE (1995) The history of synthetic testosterone. Sci Am 272: 76-81.

15. Compiled data from IMS Health Incorporated (2010) Milestones of TRT Research and Development.

16. Freeman ER, Bloom DA, McGuire EJ (2001) A brief history of testosterone. $J$ Urol 165: 371-373.

17. Greenspan, Francis S, Gardner, David G (2004) Basic and Clinica Endocrinology. Lange Medical Books, McGrawHill.

18. Kim ED, Crosnoe L, Bar-Chama N, Khera M, Lipshultz LI (2013) The treatment of hypogonadism in men of reproductive age. Fertil Steril 99: 718-724.

19. Walker WH (2010) Non-classical actions of testosterone and spermatogenesis. Philos Trans R Soc Lond B Biol Sci 365: 1557-1569.
This article was originally published in a special issue, Hormonal Therapy handled by Editors. Dr. Ratna K Vadlamudi, University of Texas San Antonio, TX, USA; Dr. Baharudin Bin Abdullah, School of Medical Sciences, Health Campus USM, Malaysia 